\title{
ZOOMING OUT: ACTOR ENGAGEMENT BEYOND THE DYADIC
}

\begin{abstract}
Purpose: The aim of this paper is to broaden extant understanding of actor engagement behavior beyond its currently dominant dyadic (micro-level) focus, by examining it from multiple levels of aggregation within a service ecosystem framework.

Design/methodology/approach: This conceptual paper draws on service-dominant logic and structuration theory as theoretical lenses to inform engagement research.

Findings: By means of a stepwise exercise of 'zooming out,' the paper introduces a multiperspective (micro-, meso-, macro- and meta-level) view of actor engagement that develops understanding of multiple engagement contexts, and suggests that balancing multiple roles may result in actor disengagement behavior. The role of reference groups and role conflict associated with balancing multiple roles is critical to understanding why engaged actor proclivities may wax and wane between contexts.
\end{abstract}

Research limitations/implications: The paper offers a set of five propositions that can be utilized by engagement scholars undertaking further research in this area.

Practical implications: Firms need to understand the values and norms embedded in diverse engagement contexts which can affect actor groups' needs and motivations. Firms should develop appropriate organizational mechanisms to facilitate (rather than impede or obstruct) the desired behaviors of engaged actors.

Originality/value: The broader context within which engaged actors operate, and its effects on engagement, has been largely overlooked to date. By broadening the analytical perspective on engagement beyond the dyadic this paper reveals previously unaddressed aspects of this phenomenon, such as the role of disengagement behavior, and the effects of multiple engagement contexts on actors' future behaviors.

Keywords: Actor engagement, customer engagement, roles, service ecosystems, servicedominant logic, structuration

Article type: Conceptual paper 


\section{ZOOMING OUT: ACTOR ENGAGEMENT BEYOND THE DYADIC}

\section{Introduction}

Research on engagement has grown in significance and impact in recent years highlighting both its theoretical and practical importance (Harmeling et al., 2017; Venkatesan, 2017). Despite the concept's previous utilization in a range of academic domains (see Brodie et al., 2011a), its adoption in marketing remains relatively recent (Brodie et al., 2011a; Verhoef et al., 2010; Jaakkola \& Alexander, 2014; Hollebeek et al., 2014). Within the marketing domain, an individual's engagement has been characterized as emotional bonding that extends beyond loyalty and satisfaction (Kumar \& Pansari, 2016), functioning as an important precursor for customer contributions to a wide range of firm-shaping functions (Jaakkola \& Alexander, 2014; Harmeling et al., 2017); or actors' value cocreation activities (Storbacka et al., 2016).

Thus far, the analytical focus of engagement research has predominantly been on the micro level, concerned with individual customers and their relationships with specific focal objects, such as products, firms, or brands. This focus has allowed researchers to capture the nomological nature of engagement, i.e. antecedents for and consequences of engagement for the customer or the firm (see Brodie et al., 2011). However, the broader context within which the individual operates and the effects thereof on engagement has been largely overlooked to date. Indeed, broadening the scope of engagement research from customers to the broader notion of actors; from dyads to networks; and from micro to meso, or macro, level of aggregation is increasingly called for (e.g. Brodie et al., 2016; Storbacka et al., 2016; Breidbach \& Brodie, 2017; Li et al., 2017). In addition, engagement is increasingly recognized as an important mid-range concept bridging the empirical domain of knowledge with the meta-theoretical lens of Service-Dominant Logic (S-D Logic; Vargo \& Lusch, 2017; Brodie et al., 2011b). S-D Logic thus offers a natural theoretical basis for broadening the scope of engagement research.

Broadening the analytical perspective on engagement 'beyond the dyadic' reveals aspects of this phenomenon that have remained unaddressed in previous research. An ecosystem view highlights that each actor is involved in a multitude of co-existing value creation processes with other actors (Vargo \& Lusch, 2016), suggesting that they face multiple, potentially conflicting, contexts in which they are engaged (hereafter 'engagement contexts'). While extant research offers valuable insight into a range of individual actors' engagement, to date, it has not considered how different engagement contexts are connected to one another and, 
importantly, how an individual (actor) is able to coordinate their engagement with multiple objects simultaneously (Dessart et al., 2016). What is missing, therefore, is a broader perspective on engagement that takes account of the various context(s) within which individual engagement behaviors are embedded. Based on Vargo and Lusch's (2017, p. 13) observation that "one cannot fully understand the activity at one level without viewing it from another," the aim of this paper is to broaden extant understanding on actor engagement, beyond its currently predominantly dyadic (micro-level) focus, by examining it from multiple levels of aggregation (Vargo \& Lusch, 2017).

Thus, the paper zooms out from the micro-level, by using what Chandler and Vargo (2011) term oscillating foci to explore engagement from different levels of aggregation. To achieve this aim, literature on S-D Logic and structuration theory provide the necessary levels of aggregation (micro - meso - macro) with the service eco-system as the main unit of analysis. Further, literature on role conflict, institutional work, social influence and reference groups are deployed to offer additional insight. In line with the broader evolution of engagement research (Storbacka et al., 2016; Brodie et al., 2016), the analyses are not limited to customers, but encompass any actor type in the service ecosystem; hence the term 'actor engagement' is used.

This paper offers a number of contributions to engagement research. First, the analytical exercise of 'zooming out' enables consideration of the institutional context within which actor engagement is embedded (Vargo \& Lusch, 2017), an issue that is yet to receive attention. Second, this paper expands beyond dyadic engagement interactions, by examining actors' parallel engagement with multiple objects, highlighting how engagement is triggered, shaped, and ceased due to the relative congruence of relevant institutional settings, the social influence within specific reference groups, and the degree of perceived conflict for actors balancing the (perceived) requirements inherent in multiple engagement contexts. In the analyses, the concept of "actor disengagement behavior" is developed, and its triggers are considered, marking this paper's third key contribution. Firms will consequently need to understand the values and norms embedded in different engagement contexts that affect each of the relevant actor groups' needs and motivations, and subsequently develop organizational mechanisms that facilitate (rather than impede or obstruct) the desired behaviors of each actor group.

The paper proceeds by exploring customer engagement at various levels of aggregation, through oscillating foci. This zooming out process begins by exploring a priori understanding of customer/actor engagement at the micro level, focusing on a single engagement object. Subsequently engagement located at the meso- and macro-levels of aggregation as 
considered. Here, engagement activities are shaped and influenced by their wider service ecosystems; that is, institutions and institutional arrangements (Vargo and Lusch, 2016). Finally, the paper zooms out further to encompass the multiple service ecosystems hosting a multitude of engagement contexts that any individual actor might experience. Finally, important theoretical and managerial implications are discussed, and a research agenda for future work in the area is developed.

\section{Micro-level view of actor engagement}

In the marketing domain, the idea of customer engagement (CE) as a discrete concept emerged from a growing understanding of an interconnected marketplace with increasing collaboration and interaction (Brodie et al., 2011a), leading to a blurring of traditional roles whereby customers are proactively engaged in organizational activities (Jaakkola \& Alexander, 2014; Harmeling et al., 2017). Brodie et al. (2011a) offer conceptual foundations of engagement that are condensed in a set of five Fundamental Propositions encapsulating: engagement as a psychological state that occurs within a dynamic, iterative engagement process; cognitive, emotional and behavioral dimensions of engagement; the central role of engagement within a nomological network of service-based conceptual relationships; and, engagement occurring within specific contextual conditions.

As indicated, existing engagement research has, thus far, predominantly adopted micro level analyses, examining individual actors' (mainly customers') engagement toward a firm or a brand - typically by exploring the cognitive, emotional and behavioral dimensions - or specific, identifiable behavioral manifestations that act as outcomes from this psychological state. These are next discussed.

\subsection{Engagement as a psychological state}

In their influential article, Brodie et al. (2011a) define customer engagement as an individual's psychological state. Similarly, actor engagement may be viewed as an individual's state of mind, or disposition (Storbacka et al., 2016) reflecting the extent of their engagement with a particular focal object (e.g. a brand, firm, salient others, etc.; Appleton et al., 2006; Koch, 1997). In the marketing literature, actors' (predominantly customers') psychological engagement has been thought to contribute to important organizational outcomes, including enhanced customer brand commitment, satisfaction, loyalty and emotional bonding with brands (Brodie et al., 2011a; Hollebeek et al., 2014). Extending this notion to the conceptually broader 'actor engagement' concept, one might expect actors' particular psychological state to impact upon their ensuing commitment, loyalty and bonding with focal objects, leading to engagement (Brodie et al., 2016). For example, a new mother 
feels an intensive connection and heightened interest (e.g. Vivek et al., 2012) towards a brand of organic baby food, and holds a high level of cognitive and affective (i.e. psychological) engagement with, and active commitment towards, maintaining an active relationship with this brand beyond the basic purchase (Van Doorn et al. 2010; Hollebeek, 2011b). Over time, a series of aggregated engagement states form a broader engagement process (Hollebeek et al., 2016; Brodie et al., 2011a).

\subsection{Behavioral manifestations of engagement}

Extant research posits that although engagement is a multidimensional phenomenon comprising emotional and cognitive components (Brodie et al., 2011a), among others, it is through customer engagement behaviors (CEBs) that engagement affects other actors (Van Doorn et al., 2010; Jaakkola \& Alexander, 2014). Consistent with Brodie et al (2011a) the term 'object' is used to denote that which is engaged with (e.g. a product, brand, person) by an engagement subject (e.g. customer, citizen). Engagement behavior reflects actors' specific resource investments (e.g. time, energy and effort) into interactions with a focal engagement object (Hollebeek et al., 2016; Sweeney et al., 2015; Hollebeek et al., 2014). It is important to note that extant literature views engagement behavior as a voluntary resource contribution that go beyond transactions (Jaakkola \& Alexander, 2014; Harmeling et al., 2017). In essence, CEB conceptualize customers 'exogenously, driven by their own unique purposes and intentions' (Jaakkola \& Alexander, 2014, p.248), rather than acting on the firm's behest (e.g. in-role behavior, co-production). Therefore, while actor engagement reflects actors' cognitive (e.g. a supplier's firm-related thoughts), and emotional (e.g. a customer's positive brand-related affect) resource investments integrated with a view to achieving particular value-creating objectives (Hollebeek et al., 2016), actor engagement behaviors (AEBs) reflect actors' voluntary, behavioral investments in focal object interactions to create value (Verleye et al., 2014).

Engagement research delineates the behavioral manifestations of engagement as customer actions that can either, in some way, affect the engagement object (e.g. the firm, brand), go beyond behaviors elementary to purchases (Van Doorn et al., 2010; Verleye et al., 2014), or even occur outside traditional exchange relationships (Groeger et al., 2016). In addition, Jaakkola and Alexander (2014) reveal how CEBs contribute to broader value co-creation by accruing value for engagement subjects, objects and/or other ecosystem actors via diverse resource contributions gained through exchange and interaction. This systemic view of engagement aligns with a move toward a more generic Actor-to-Actor configuration (A2A, as opposed to B2C etc., see Vargo \& Lusch, 2016). Storbacka et al. (2016) use the broader term 'actor engagement' to encompass any activity of engaging in the interactive resource 
integration processes. A view reconciling both perspectives sees actor engagement as involving focal actors' resource contributions - potentially beyond what is elementary to fundamental interactions - leading to an interactive resource integration process. Synthesizing previous works on CEB (Van Doorn et al., 2010; Jaakkola \& Alexander, 2014; Storbacka et al., 2016; Groeger et al., 2016), this paper offers a broad definition of AEBs as 'an actor's voluntary resource contributions that focus on the engagement object, go beyond what is elementary to the exchange, and occur in interactions with a focal object and/or other actors.' Essentially, an engaged actor is disposed to invest a broad range of resources - such as time, money, information, labor - with a focus on the focal engagement object (e.g. a product, brand), and these resource contributions occur through specific, interactive engagement behaviors.

Empirical investigation into engagement behaviors remains scarce. Engagement literature typically discusses various customer activities that affect firm functions, including customer acquisition or new product development (e.g. Van Doorn et al., 2010; Harmeling et al., 2017). Jaakkola and Alexander (2014, p. 9) classify CEBs into four broad categories: (i) Augmenting behavior, where customers contribute such resources as knowledge, skills, labor, and time that directly augment and add to the focal firm's offering; (ii) Codeveloping behavior, where customers contribute knowledge, skills, and time, to facilitate the focal firm's development of its offering; (iii) Influencing behavior that refers to contribution of resources to affect other actors' perceptions, preferences, or knowledge regarding the focal firm; and (iv) Mobilizing behavior, where customers contribute such resources as relationships and time to mobilize other stakeholders' actions toward the focal firm.

These broad categories are also likely to have applicability to the broader actor engagement context; by indicating that an actor may contribute directly to a focal object (i.e. i and ii above), or influence other actors' attitudes or behaviors towards the object (i.e. iii and iv above). This influence may be positively valenced (e.g. through the focal actor making favorable object-related investments), or negatively valenced (e.g. with the focal actor making undesirable brand-related investment, e.g. by expressing negative word of mouth; Bowden et al., 2017; Hollebeek \& Chen, 2014), potentially diminishing other actors' engagement (Naumann et al., 2017). Noteworthy is that through AEBs, actors not only contribute resources towards the focal engagement object, but also - directly or indirectly towards other service ecosystem actors (Jaakkola \& Alexander, 2014). In terms of the organic baby food example, the engaged actor may recommend the brand to other parents in an online parenting related discussion forum (e.g. the UK's popular 'mumsnet ${ }^{l}$ ' a website for parents

\footnotetext{
${ }^{1}$ https://www.mumsnet.com/
} 
that includes multiple discussion forums on a range of topics). Alternatively, parents can engage with firms directly to give suggestions regarding new taste varieties or packaging. This way, customers may also affect other parents' perception of the product, and contribute valuable information to the firm that can be used to improve its product range or presentation. In sum, the micro view focuses on the dyadic relationship between the individual actor and the engagement object. Thus far, extant research has generated both conceptual and empirical insight into customer engagement as an actor's psychological state, as well as its behavioral manifestations, focusing almost exclusively on consumers (see Table 1).

\section{Zooming out beyond the dyadic: Meso- and macro-level views of engagement}

Next, the paper zooms out to a wider level of aggregation, arguing that AEBs do not occur in isolation, but within service ecosystems that incorporate networked actors and multiple, recurring dyadic, triadic, etc. interactions (Vargo \& Lusch, 2017). Here, the ecosystem lens is drawn from S-D Logic, principally the notion of institutions and institutional arrangements (Axiom 5), as well as closely aligned structuration theory (Vargo \& Lusch, 2016). Additionally, literature on reference groups and institutional work is drawn on to elaborate on the nature of institutions in the context of engagement.

\subsection{Service Eco-Systems, Institutions and Engagement}

The service ecosystem concept originates from Alderson's (1965) pioneering research advocating the adoption of a framework of cultural ecology for the study of marketing systems, thus creating a broad, networked view of marketing. This conceptual zooming-out has generated a theoretical shift toward the adoption of a systems orientation based on the premise of interconnected actors and objects within specific systems (Vargo \& Lusch, 2016; Munro, 2009). The 'ecosystem' concept reflects a community of living organisms that share the environment with specific non-living components (e.g. air, soil, man-made artefacts, such as computers), and as a whole, interact as a system (Hatcher, 1990). Ecosystems host a network of interactions among organisms, and between organisms and their environment, which can be of any size or scope (Schulze \& Mooney, 2012). Ecosystems thus encompass other (smaller) ecosystems, giving a 'nested' view (Klijn, 1994). For S-D Logic, the service eco-system is the principal unit of analysis (Vargo \& Lusch, 2017) and offers a suitable lens for developing a broader understanding on actor engagement as it allows its embedded and interconnected nature as well as underlying structures to emerge.

Service ecosystems are defined in S-D Logic as a "relatively self-contained, self-adjusting system of resource-integrating actors connected by shared institutional arrangements and mutual value creation through service exchange," (Lusch \& Vargo, 2014, p. 161). Critical to 
a study of engagement beyond the dyad is the principle that service ecosystems are multilevel in nature. Micro-level interactions give rise to a meso-system which, in turn creates a broader macro-level structure (Lusch and Vargo, 2014). Crucially, the creation of a macrolevel system is precipitates a downward influence on lower (meso and macro) levels over time and varies with each particular context (Lusch \& Vargo, 2014). The service ecosystem definition above highlights the important role of institutions and institutional arrangements. Institutions are defined as 'humanly devised rules, norms, and beliefs that enable and constrain action and make social life at least somewhat predictable and meaningful" (Vargo and Lusch, 2016b, p. 11). Institutional arrangements are "interrelated sets of institutions that together constitute a relatively coherent assemblage that facilitates coordination of activity in value-cocreating service ecosystems." (Vargo and Lusch, 2016a, p. 18). In essence, institutions and their higher-order assemblages (i.e. institutional arrangements) provide context that guides actors' actions and interactions, and these both enable and constrain service exchange (Edvardsson et al., 2011).

While engagement research has to a large extent perceived engagement as an actor's innate, personal disposition, an ecosystem lens highlights the role of context, with its institutions and institutional arrangements that provide rules, norms and practices for actor engagement. The context for each actor introduces norms and values that influence actor engagement behaviors and perceptions of value; that is, the way they contribute and integrate resources is determined by service ecosystem boundaries, as well as their positions and roles associated with particular service ecosystem-based institutions and institutional arrangements (Edvardsson et al., 2011; Koskela-Huotari \& Vargo, 2016).

The nature of institutions depends on the level of zooming out; institutions potentially more relevant for AEB are specific to the meso-level (e.g. brand community), while broader macro-level institutions include rules and norms, such as legislation and cultural practices (cf. Vargo \& Lusch, 2016). Engagement towards a focal object (e.g. a brand) is characterized by interactions between actors, who tend to undertake similar activities (e.g. through a shared passion or interest; Brodie et al., 2013; Schau et al., 2009). For example, the mother demonstrating high engagement towards organic baby food is prone to discuss and debate infant nutrition issues with other like-minded parents and friends, in both online and offline contexts and might, as a result, adjust her AEB toward an engagement object.

In social science, group membership is recognized as a key determinant of behavior with individuals acting "in accordance with a frame of reference produced by the groups to which they belong" (Bearden \& Etzel, 1982). Reference groups do not necessarily require specific social ties, all that is needed is a favorable attitude towards members of a particular group 
(Bearden \& Etzel, 1982). Lapinski and Rimal (2005) note that an assessment of the extent to which others engage in a specific behavior plays an important role in an individual actor's decision-making process. Conforming to a specific social norm is often deemed the most appropriate course of action and serves as a form of decision-making heuristic (Lapinski \& Rimal, 2005). For the mother in the earlier example, the opinions and 'truths' formed and shared in an online discussion forum on parenting may constitute key heuristics for particular types of infant nutrition to favor and/or advocate.

Lapinski and Rimal (2005) refer to different levels of social norms (i.e. institutions) that affect an individual. Collective norms operate at the systemic level and imply codes of conduct for collective entities which could be specific social networks or entire societies. Injunctive norms relate to specific beliefs held about the correct course of action in a specific situation, and descriptive norms relate to what is done in a specific actor's social group. Lapinski and Rimal (2005) further suggest that this influence is stronger when the actor identifies with the specific reference group, and when there is ego-involvement, a motivational state induced by an association between an activated attitude and some aspect of the self. In other words, the norms originating from reference groups may impart a stronger effect on AEB when the focal actor - such as the mother in the example above - closely identifies themselves with the reference group (e.g. other parents), and the issue of parenting is a key part of their self-identity.

\subsection{Actor Engagement institutions and interdependency}

As discussed earlier, previous engagement research has predominantly studied engagement as independent from its broader context, at a dyadic, micro level. However, in S-D Logic, Vargo and Lusch (2016) use structuration theory to provide an underlying foundation to examines the creation and reproduction of social systems (Giddens, 1984); that is, routinized, repeated actions that have meaning to those in the in-group (Schau et al., 2009; Akaka et al., 2015). Applying structuration theory to engagement research acknowledges that interdependency (duality) exists between structure and agency: While structure, to some extent, governs actor behavior, individuals' actions not only are enforcing, but also changing the structure (Battilana et al. 2009; Vargo \& Lusch 2016). Kjellberg and Helgesson (2006) describe markets as being continually formed and re-formed through the activities of economic actors who perform specific sets of interconnected practices. Similarly, through their activities, actors build, interpret, modify, and accommodate institutional arrangements; thus reflecting the dynamic and evolving nature of institutional arrangements (DiMaggio, 1988; Lawrence \& Suddaby, 2006; Battilana et al., 2009). Institutional arrangements, consequently, not only shape, but are also shaped by, actors' activities. 
In this sense, AEBs are akin to a form of institutional work, a concept also relevant for a S-D Logic lens (Koskela-Huotari et al., 2016; Vargo et al., 2015). Institutional work is defined as 'the purposive action of individual and collective actors aimed at creating, maintaining and disrupting organizations' (Lawrence et al., 2011, p.11). The concept resonates with a structurationist framework and engagement as it supports the notion of actors both maintaining institutions but also transforming them through disruptive 'work.' Importantly, literature on institutional work not only encompasses entrepreneurial or innovative actions on a grand scale (Lawrence et al., 2011), but also actors' actions and their transformative potential. Thus, change wrought through institutional work can be highly visible and dramatic but most often is perhaps incremental and less visible. Put in an engagement context, an individual actor's engagement behavior, as a form of institutional work, either reinforces or maintains the institution or enforces institutional change through disruption (cf. Battilana et al., 2009; Koskela-Huotari et al., 2016)

For the organic baby food example, at a meso level, these would include, for example, the beliefs, values and norms regarding healthy infant nutrition or dangers of genetically modified or processed foods shared among members in a parenting discussion forum; and the wider practices of eating in particular cultural setting. In other words, through engagement with a brand community like mumsnet, parental perception of what is acceptable and 'good' are calibrated through its beliefs and values, but at the same time, through engagement behaviors these actors reinforce or change norms. For example, past successful mumsnet campaigns have included lobbying major retailers to keep magazines with overtly sexualized cover images out of children's eye lines in shops; and asking retailers not to sell clothes that play upon, emphasize or exploit a young girls' sexuality. Both these campaigns resulted in major UK retailers 'signing up' to the demands. ${ }^{2}$

At a macro level, this view would highlight not only the organic baby food setting, but also that of other baby products, including children's clothing or equipment such as prams or cots. Here, each context and its associated set of institutions (e.g. norms posed by the reference group of the actor) are embedded in a broader ecosystem sharing a set of broader institutional arrangements (e.g. industry standards or social norms). This zooming out makes it possible to see how AEB occurring in the micro-level can influence actors in both the close context (other customers using the same products), but also eventually at wider levels, through reproducing or altering the prevailing institutions. For example, parental pressure group 'mumsnet' has become so influential that UK politicians are regularly contributing to the site

\footnotetext{
${ }^{2}$ https://www.mumsnet.com/campaigns/mumsnet-campaigns-the-story-so-far
} 
(Philips, 2012), additionally, lobbying from the site in 2013 caused the UK government to abandon proposals to increase childcare ratios in UK schools. ${ }^{3}$

In sum, the lenses of S-D Logic, institutional work and structuration allow observation of the effect of AEB from a wider perspective (see Table 1). A service ecosystem approach informed by structuration suggests that the formation of ecosystems is both a bottom up (micro configurations coalesce into meso-level, and so on) but also, top down (macro-level 'terms of engagement' affect the meso- and micro-levels). This enables consideration of the effect of AEB beyond the dyadic, micro-level. For while AEB are dictated by their institutional context, the behaviors themselves can work upwards and influence both mesoand macro-levels of the ecosystem.

\section{Meta-level view: Multiple, parallel engagement contexts}

Finally, zooming out to reach what can be called 'meta-level' view; reveals multiple, coexisting engagement contexts that involve different service ecosystems (e.g. sectors, industries), but may share the same macro-level institutions and institutional arrangements, such as legislation and cultural norms (see table 1). As each actor is simultaneously occupying multiple engagement contexts, they are in the intersections of multiple institutional arrangements. For example, in addition to engagement towards organic baby food, the mother may exhibit high engagement towards cars or a sports team, and also hold other professional and private roles associated with a related reference group and set of institutions.

Chandler and Vargo (2011) propose that contexts frame interactions or exchanges that can be seen and understood, whereby each actor's unique qualities 'affects other actors in the context, as well as the context as a whole.' As resources are drawn upon for service across varying contexts, each context provides conditions 'under which different resources will and will not be valuable' (Barney et al., 2001: 43 cited in Chandler \& Vargo, 2011). Thus, for a broader understanding of AEB and their role beyond dyadic settings it is important to consider the multiple, parallel contexts where actors will, in many cases, be engaged or be directing engagement behaviors to more than one particular foci. This 'parallel' engagement will leave an actor exposed to specific pressures and influences that may cause them to redirect their engagement efforts or disengage from one context to another. The pressure of multiple institutional arrangements puts the actor in a position analogous to role conflict as discussed in service literature (e.g. Solomon et al., 1985), which is why role literature is used to further understand conflict experienced by an actor in the intersections of multiple engagement contexts. Next, the paper consider how actors might meet the demands of

\footnotetext{
${ }^{3}$ https://www.mumsnet.com/campaigns/mumsnet-campaigns-the-story-so-far-info
} 
multiple engagement contexts and circumstance, and argue that parallel engagement contexts trigger also actor disengagement.

\subsection{Role conflict in multiple engagement contexts}

When actors engage with multiple institutions simultaneously, they face demands, requirements and responsibilities deriving from the institutions and institutional arrangements particular to each context. In this section, circumstances when actors may experience contextual pressures or conflict are considered that may affect their propensity to engage.

An actor's role refers to those socially defined expectations of individuals' behaviors in a particular position (Solomon et al., 1985). In service research, role theory is typically used to provide insight into interactions between a customer and an organization (and those working within it). Solomon et al. (1985) relate role theory as a set of practices resulting from wellestablished social positions between actors, typically in a service encounter situation (e.g. waiter/customer). Adopted roles govern interactions within an exchange (Broderick, 1998). Within the service domain, role theory has been applied to study service encounters with the perspective of single roles allocated to actors (e.g. customer/receptionist) that are governed by well-established social norms, and are usually bound by time within a specific encounter. However, in the wider social sciences, theorizing about multiple roles is more common and concerned with an individual's finite levels of energy, and the difficulty of managing multiple roles (Marks, 1977). The difficulties individuals experience in managing multiple roles creates pressure to direct their flow of performance toward more highly valued activities and thereby over-perform in some roles, while under-performing in others (Marks, 1977).

These multiple role difficulties are explained by the term 'role conflict,' which is caused by "simultaneous occupancy of conflicting structural positions" (Stryker \& Macke, 1978). Role conflict disrupts the predictability which actors need before understanding individual actions in specific contexts due to disagreement on role expectation and a need to ascertain others viewpoints before engaging. Engagement behaviors therefore, which are largely voluntary, will be subject to the ebb and flow of an actor's proclivities and personal pressures arising from multiple engagement contexts governed by at least partially different institutions. Role conflicts are often associated within negative outcomes, which can be understood through affective or behavioral reactions (studied predominantly in employee (role) contexts, see Jackson \& Schuler, 1985). Thus, when actors attempt to balance the needs of multiple, parallel engagement contexts (and roles therein), they may experience forms of conflict or strain associated with their engagement. 


\subsection{Actor disengagement behavior and multiple parallel actor engagement contexts}

The highest levels of aggregation, achieved though 'zooming out,' are engagement contexts embedded in multiple, co-existing service eco-systems. Each engagement context and its associated reference group is associated with a unique set of institutions, which are interrelated and may, in particular circumstances, coincide, overlap and/or even conflict. This paper proposes that, as a result of inhabiting multiple parallel engagement contexts simultaneously, actors will experience a some degree of conflict as the norms, rules or activities considered desirable for one role may go against those prescribed by an actor's other role(s). Thus, engagement behaviors that are valuable in one context may be less so in another (Akaka \& Chandler, 2011). As Chandler and Lusch (2015: p. 6) state, it is "often not possible, feasible, or necessary for an actor to accept all value propositions" encountered, particularly when these relate to, or reflect, actors' differing, or potentially conflicting, activities. The outcome of this, it can be assumed, would be disengagement from one or more engagement contexts. Arguably, actor engagement and disengagement behaviors are equally important to understand as they mark the activities contributing to interactive processes between actors; or the ceasing of such. For example, a parent may start by engaging with multiple firms or engagement platforms but discovers that one parental forum does not recommend a particular baby product or firm (mumsnet, for instance, does not allow advertising from global food giant Nestlé due to its aggressive marketing of milk formula in breach of international standards), this would result in the withdrawal of resources from one engagement object. On a wider scale, an actor who is engaged with multiple engagement contexts simultaneously may require to withdraw resources from one context due to an inability to inhabit multiple contexts at the same time. This disengagement could be either temporary or permanent.

Here, actor disengagement behavior (ADB) is defined as 'an actor's temporary or permanent removal of resource contributions from a focal engagement object, which affects value processes and outcomes for the focal actor, as well as other actors within the service ecosystem.' It is important to note that ADB differ, conceptually, from negative engagement behaviors (Bowden et al., 2017; Hollebeek \& Chen, 2014), which are actors' intentional efforts to inflict negativity, harm, or damage to another actor, or actor collective, in some regard (e.g. a member of the general public, using a pseudonym, who posts harmful messages about a company's practices on social media; Paulin et al, 2014; Juric et al., 2016). ADB, by contrast, relates to a temporary or permanent withdrawal of interactivity from a focal object, which may include engagement dormancy (i.e. temporary lags in engagement; Brodie et al., 2013), or perpetual engagement termination (i.e. a permanent cessation of engagement, which could be due to changed needs, e.g. a child growing up no longer requiring infant nutrition). 
Critically, the voluntary nature of AEB mean that actors may find it easier to withdraw from specific engagement roles as a result of heightened role conflict, or as a result of a desire to follow a particular reference group, resulting in ADB. This disengagement from the focal object or, perhaps, redirection of efforts represents a form of push and pull at a meta level where an actors desire to engage or disengage from a particular context will have a ripple effect across the various ecosystems, and will reproduce or gradually disrupt institutions. For example, Alderson (1965, p. 301) views the association between structure and behavior to be determined by "rules, which are generated by interaction among the members of a system," and "rules of conduct, which grow out of interaction among separate systems." Thus, actor engagement behaviors in one service ecosystem may affect also others, leading to institutions developing and evolving over time (Vargo et al., 2015).

\section{Conclusions}

\subsection{Theoretical implications}

The aim of this paper was to broaden academic understanding of the concept of actor engagement beyond its currently predominantly dyadic, micro-level focus (Storbacka et al., 2016), this was achieved by examining the concept from multiple levels of aggregation (Vargo \& Lusch, 2017). By means of deploying the stepwise exercise of 'zooming out,' the paper introduces a multi-perspective (micro-, meso-, macro- and meta-level) view of actor engagement that develops understanding of multiple engagement contexts and their effects on individual actors' engagement- and disengagement behaviors. This paper demonstrates that, depending on the level of aggregation, researchers adopt particular research foci and are able to illuminate different aspects of engagement, as summarized in Table 1. This analysis suggests that given the predominant micro level focus of extant engagement research, institutional contexts - as well as the existence of multiple, parallel engagement contexts - has not yet been adequately addressed. Next, a set of research propositions are developed to summarize the arguments of this study laying a foundation for engagement research adopting an analytical focus beyond the dyadic. The following sections also explicate three key contributions to the domain of engagement research and managerial implications.

---Insert Table 1 here---

First, this paper contributes to the literature by highlighting the role of the institutional context within which engagement is embedded, an issue that has received little exploration in previous customer/actor engagement research. This paper proposes that (P1): Institutions and institutional arrangements define expected actor engagement behaviors in a particular 
engagement context. Previous engagement research has limited its analyses to the role of institutions only implicitly, such as in terms of brand community practices (e.g. Schau et al., 2009; Brodie et al., 2013). The paper provides a holistic view by proposing that AEB and ADB emerge, and continuously evolve, in the interplay of multiple - and potentially conflicting - engagement contexts governed by focal institutions, institutional arrangements, and broader service ecosystems, reinforcing the conceptual relationship between S-D Logic and engagement. These notions contribute to thus far limited research into more collective, networked or institutional engagement dynamics (Chandler \& Lusch, 2015), which remain poorly understood to date.

Second, this paper expands beyond dyadic engagement relationships that dominate published research to date, by examining actors' parallel engagement with multiple engagement objects simultaneously. It is proposed that (P2): Actors balance multiple, parallel engagement contexts whereby they manage potential tensions between focal institutions and institutional arrangements relevant to each of these contexts. Thus, each actor is likely to deploy multiple, oscillating engagement foci (objects) that exist in parallel. Further, in each context, actors can exhibit multiple AEBs, which may vary in intensity and/or valence; a view that has been missing from engagement research thus far. Service ecosystem actors' multi-context view reflects the complex, interwoven nature of multiple actor roles and behaviors, which resonates well with existing marketing thought (e.g. many-to-one, one-to-many, many-tomany, etc. interactions; Storbacka et al., 2016; Marks, 1977; Jahn \& Kunz, 2012).

Third, this paper develops the concept of "actor disengagement behavior," building on pioneering work on AE (Storbacka et al., 2016; Chandler \& Lusch, 2015), and engagement behaviors (Van Doorn et al., 2010; Jaakkola \& Alexander, 2014). From the zoomed out, meta-level view, it is possible to view multiple service ecosystems and reveal how engagement can fluidly transition into disengagement (Naumann et al., 2017), and/or convert or evolve from, or into, the other (Echeverri \& Skålén, 2011; Hollebeek et al., 2014). The potential for role conflict to emerge from actors' attempts to inhabit and balance the demands of multiple engagement contexts and respective institutional arrangement may result in a shifting of engagement from one context to another or, alternatively, temporary or permanent disengagement from their focal engagement object (Brodie et al., 2013).

The third proposition (P3) is as follows: Actor disengagement behavior is an actor's temporary or permanent removal of resource contributions from the engagement object. Further, the analysis of engagement from multiple levels of aggregation enables elaboration on the nature and influence of actor engagement behavior. AEBs are voluntary actor activities that are based on underlying motivational drivers (Van Doorn et al., 2010; Jaakkola \& 
Alexander, 2014; Hollebeek et al., 2016), governed by institutions and institutional arrangements relevant to the engagement context. Influenced by these institutions, actors choose to integrate (or withhold) particular operant and/or operand resources, thereby producing focal AEBs through focal object interactions (Brodie et al., 2011). Here, proposition 4 states (P4): Actor engagement behaviors are triggered, shaped, and also ceased as a result of the degree of conflict experienced when balancing multiple engagement contexts. These findings add to previous engagement research that lacks insight into actors' intentional ceasing of engagement, despite the obvious managerial and theoretical relevance of this question.

ADB also plays a role in the forming and reforming of institutions. The observable regularities of social systems - that is, institutions and institutional arrangements - exist only as long as they are re-created through social activity over time (cf. Giddens, 1984; Edvardsson et al., 2011). When institutions are not reinforced by actors' behaviors, they may be 'de-institutionalized' (Oliver, 1992), indicating that AEBs and ADB may be/are equally important in the development (or dissolution) of institutions as a form of institutional work (Lawrence et al., 2011). Clearly, an actor's disengagement from one context may also result in the individual engaging, re-engaging, enhancing or reducing the level and/or valence of their engagement in other contexts, thus rendering the study of disengagement an important future research area.

The notion that individual customer interests can wax and wane from one brand or firm to another is not new (e.g. as tastes change, so do related buying and usage habits). However, when an individual stops buying a particular product or service there is only a single dyadic effect, directed towards the focal brand or firm. However, it is the networked, interactive nature of AEBs that enhance the impact of any oscillations. Engagement behaviors have the capacity to affect other actors' feelings or direct actions toward a focal object (Alexander \& Jaakkola, 2016); if these behaviors wane, then it is not just the individual customer's relationship with the focal object that is affected but, there may be much wider, systemic effects. This leads to proposion P5: Through (dis)engagement behaviors, actors contribute or withdraw resources related to the focal engagement object that gradually reinforce and/or change institutions and institutional arrangements particular to focal engagement contexts, thereby eventually affecting other actors' engagement.

Together, these notions broaden extant understanding on actor engagement that has been examined primarily from a micro-level perspective; that is, by focusing on individual engagement contexts. This study is among the first attempts to consider how different 
engagement contexts are connected to one another and, importantly, how individual actors are able to coordinate multiple engagement contexts simultaneously.

\subsection{Managerial Implications}

This research highlights the benefits of zooming engagement research out from its predominately micro-level focus to date, to encompass broader levels of aggregation (e.g. the meta-level), which also has implications for firms that seek to encourage, or rely on, engaged customers. Existing research (e.g. Schau et al., 2009; Brodie et al., 2013; Bowden et al., 2017; Hollebeek et al. 2017) provides a preliminary understanding of consumers' engagement practices in the virtual brand community context. Extending this notion to the domain of $\mathrm{AE}$, actors, in executing their relevant engagement behaviors and/or disengagement behavior, or practices, tend to adopt particular routinized, habitual and/or selfregulated practices, and in doing so, tend to work with and/or around other actors in seeking to meet their needs within broader service ecosystems.

Firms, consequently, need to understand the values and norms embedded in diverse engagement contexts affecting each of the relevant actor groups' needs and motivations, and subsequently develop organizational mechanisms that facilitate (rather than impede or obstruct) the desired behaviors of each actor group. Another contribution of this view is that while engagement (behaviors) are typically desirable, in some cases actor disengagement behaviors will be paramount and/or sought (e.g. reducing social media engagement in teenagers). Further, the development of enhanced understanding of these (dis)engagement behavior(s)s for particular actor groups, and their underlying motivations, can thus help managers to better understand actors' respective (dis)engagement motivations, triggers and inhibiting factors, which can, in turn, contribute to enhanced actor relationships and returns.

This research can also assist organizations by allowing them to better understand the mechanisms by which engaged actors form, develop and influence service eco-systems. By cultivating their own rules (institutions), engaged actors not only influence individual other actors (micro-level), collective actors (e.g. in a firm; meso-level), but also at a broader, macro-level, such as national governments. For example, customer collectives lobbying against specific government legislation may be able to exert particular pressures that will impact on a product's ecosystem and supply chains (e.g. lobbying to reduce calories in packaged food). To illustrate, the mumsnet example shows how the brand community influences individual parents' views on bringing up their children, targets specific firms and product types, and enacts progress at the governmental level through legislative changes. This wider, ecosystem view of engagement should encourage firms to adopt a broader 
understanding of the role of engaged actors in their organizations, and their respective returns, including bottom line, double-bottom line and triple bottom line returns.

Understanding the dynamic relationship between AEB and ADB will be of interest to organizations across a broad range of sectors, and dealing with balancing the needs, interests and outcomes related to a broad range of actors. This paper introduces the notion of (dis)engagement's fluid nature into the literature. Specifically, actors may struggle (over time) to satisfactorily engage in multiple engagement contexts. Specifically, each actor's own unique configuration of engagement contexts (with associated reference groups and conflict) suggests that engaged actors may be prejudicing one role over another (Marks, 1977; Shamir, 1980). Recent research (e.g. Harmeling et al., 2017) highlights the importance of engagement marketing, which, coupled with the notion of total engagement value (Kumar et al., 2010) suggests that firms, in the near future, need to adopt an engagement-based strategic mindset, not only from customers, but also from other types of actors, including suppliers, the general public, regulators, etc. that takes into account actors' engagement, as well as disengagement, and potential transgressions between these. For example, TripAdvisor sends out emails to participants who have not reviewed for a while to remind them of the ongoing impact of their reviews, and request further reviews from them. Essentially, the potential for disengagement, as much as engagement (and the importance of capturing engagement value) means that firms need to ensure they develop and retain engaged actors on an ongoing basis (Kumar et al. 2010).

In summary, if organizations understand the effect of multiple, parallel engagement contexts within which actors are engaged, they can work to create improved engagement contexts, including through engagement platform facilitation and/or other support mechanisms, thus resulting in engagement-conducive (and disengagement-reductive) institutions and institutional arrangements. Given this backdrop, this paper has key implications in societies where customer labor, often of a voluntary nature, is increasingly endogenous to governmental, commercial and charitable organizations to supplement their activities. As a result, the support provided to engaged actors becomes critical, if particular modes engagement are likely to be in any way transient and/or fragile. Finally, the development of a sound understand of what constitutes an engaged actor - and how to nurture and retain these across particular engagement contexts also remains critical for managers.

\subsection{Future research implications}

As Table 1 illustrates, engagement research to date, has been largely conceptual or focused around dyadic settings (micro level). This paper reveals new insights on engagement that can be gained by zooming out and using the service ecosystem lens to consider meso, macro or 
meta level issues relevant for engagement researchers. By zooming out, researchers can highlight the dynamic, inherently systemic nature of AEBs and ADB, and their co-evolution with their surrounding service ecosystem and its associated sub-structures, including focal institutions and institutional arrangements. In particular, the interdependent relationships that exist between actors and their ecosystem-based environment render the relevance of future investigation into this area. New insight can be gained by drawing on, for example, actornetwork theory, which views actors and objects as interdependent parts of interactive social networks (Munro, 2009). Future researchers may seek to explore factors that give rise to AEBs transitioning or shifting into ADB, or vice versa (Echeverri \& Skålén, 2011), and the key consequences therein (e.g. in terms of a focal actor's commitment toward an agent or object; Hollebeek et al., 2014). Future (empirical) research can also explore the development and evolution of AEBs and ADB, as well as actor roles, including their antecedents, change process and key effects over time within service ecosystems.

This research also highlights the value of considering engagement behaviors as a finite or temporal resource with customers transitioning in and out of focal engagement contexts, or shifting resources from one context to another. This suggests a need for further research that considers the focal engagement dynamics as exposure to specific reference groups, and social influences will undoubtedly affect actors' engagement motivations.

In their most recent paper Vargo and Lusch (2017, p. 39) ponder: "How can strategic planning and implementation be cocreated with multiple stakeholders and what is the impact of these cocreation processes on the firm and its stakeholders?" The confluence of S-D Logic and AEB indicates how engagement behaviors are influenced but, crucially, can influence, networks of actors and wider institutions. The ways in which firms should create, facilitate and react to engagement behaviors within a service ecosystem are also of increasing importance for future research. Finally, this paper is among the first to recognize that actors are often forced to inhabit and balance the demands of multiple engagement contexts, resulting in such tensions through reference groups or role conflict. It is out of this paper's scope to consider under what circumstances these might occur or, indeed, at what point they might engender ADB. Future research in this area is therefore also critical.

\section{References}

Akaka, M.A. and Chandler, J.D. (2011), "Roles as resources: A social roles perspective of change in value networks", Marketing Theory, Vol. 11 No. 3, pp. 243-260.

Akaka, M.A. Vargo, S.L. and Schau, H.J. (2015), “The context of experience”, Journal of Service Management, Vol. 26 No. 2, pp. 206-223. 
Alderson, W. (1965), Dynamic marketing behaviour, Richard D. Irwin, Homewood.

Alexander, M. and Jaakkola, E. (2016), "Customer engagement behaviours and value cocreation", in Brodie, R.J., Hollebeek, L.D. and Conduit, J. (Eds.), Customer Engagement: Contemporary Issues and Challenges, Routledge, Abingdon, pp. 3-20.

Algesheimer, R. and Gurau, C. (2008), "Introducing structuration theory in communal consumption behavior research", Qualitative Market Research: An International Journal, Vol. 11 No. 2, pp. 227-245.

Appleton, J.J., Christenson, S.L., Kim, D. and Reschly, A.L. (2006), "Measuring cognitive and psychological engagement: Validation of the student engagement instrument", Journal of School Psychology, Vol. 44 No. 5, pp. 427-445.

Battilana, J., Leca, B. and Boxenbaum, E. (2009), "How actors change institutions: Towards a theory of institutional entrepreneurship", Academy of Management Annals, Vol. 3 No. 1, pp. 65-107.

Bearden, W. O., and Etzel, M. J. (1982), "Reference group influence on product and brand purchase decisions", Journal of Consumer Research, Vol. 9 No. 2, pp. 183-194.

Bowden, J., Conduit, J., Hollebeek, L., Luoma-Aho, V. \& Solem, B. (2017), “Engagement Valence Duality and Spillover Effects in Online Brand Communities," Journal of Service Theory and Practice, Vol. 27 No. 4, pp. 877-897.

Breidbach, C. F., \& Brodie, R. J. (2017). "Engagement platforms in the sharing economy: conceptual foundations and research directions". Journal of Service Theory and Practice, Vol. 27, No.4, pp. 738-760.

Broderick, A.J. (1998), "Role theory, role management and service performance", Journal of Services Marketing, Vol. 12 No. 5, pp. 348-361.

Brodie, R.J., Hollebeek, L.D., Juric, B. and Ilic, A. (2011a), “Customer engagement: Conceptual domain, fundamental propositions, and implications for research", Journal of Service Research, Vol. 14 No. 3, pp. 252-271.

Brodie, R. J., Saren, M., \& Pels, J. (2011b), “Theorizing about the service dominant logic: The bridging role of middle range theory", Marketing Theory, Vol. 11 No. 1, pp. 7591.

Brodie, R. J., Ilic, A., Juric, B., \& Hollebeek, L. (2013), “Consumer engagement in a virtual brand community: An exploratory analysis", Journal of Business Research, Vol. 66 No.1, pp.105-114.

Brodie R.J., Fehrer J.A., Jaakkola E., Conduit J. and Hollebeek L.D. (2016), "From Customer to Actor Engagement: Exploring a Broadened Conceptual Domain." 45th European Marketing Academy Conference (EMAC), Oslo, Norway.

Chandler, J. D., \& Vargo, S. L. (2011), "Contextualization and value-in-context: How context frames exchange", Marketing Theory, Vol. 11 No. 1, pp. 35-49. 
Chandler, J.D. and Lusch, R.F. (2015), "Service systems: A broadened framework and research agenda on value propositions, engagement, and service experience", Journal of Service Research, Vol. 18 No. 1, pp. 6-22.

Dessart, L., Veloutsou, C. \& Morgan-Thomas, A. (2016), "Capturing Consumer Engagement: Duality, Dimensionality, and Measurement," Journal of Marketing Management, Vol. 32 No. 5-6, pp. 399-426.

DiMaggio, P.J. (1988), "Interest and agency in institutional theory”, in Zucker, L. (Ed.), Institutional patterns and organizations: Culture and environment, Ballinger, Cambridge, pp. 3-21.

Echeverri, P. and Skålén, P. (2011), "Co-creation and co-destruction: A practice-theory based study of interactive value formation”, Marketing Theory, Vol. 11 No. 3, pp. 351-373.

Edvardsson, B., Tronvoll, B. and Gruber, T. (2011), "Expanding understanding of service exchange and value co-creation: A social construction approach", Journal of the Academy of Marketing Science, Vol. 39 No. 2, pp. 327-339.

Giddens, A. (1984), The constitution of society: Outline of the theory of structuration, Polity Press, Cambridge.

Groeger, L., Moroko, L. and Hollebeek, L.D. (2016), “Capturing value from non-paying consumers' engagement behaviours: Field evidence and development of a theoretical model", Journal of Strategic Marketing, Vol. 24 No. 3-4, pp. 190-209.

Harmeling, C. M., Moffett, J. W., Arnold, M. J., and Carlson, B. D, (2017) "Toward a theory of customer engagement marketing", Journal of the Academy of Marketing Science, Vol. 45 No. 3, pp. 312-335.

Hatcher, B.G. (1990), "Coral reef primary productivity: A hierarchy of pattern and process", Trends in Ecology and Evolution, Vol. 5 No. 5, pp. 149-155.

Hollebeek, L.D. (2011a), "Demystifying customer brand engagement: Exploring the loyalty nexus”, Journal of Marketing Management, Vol. 27 No. 7-8, pp. 785-807.

Hollebeek, L.D. (2011b), "Exploring customer brand engagement: Definitions and themes", Journal of Strategic Marketing, Vol. 19 No. 7, pp. 555-573.

Hollebeek, L.D. \& Chen, T. (2014), "Exploring positively- versus negatively-valenced brand engagement: A conceptual model", Journal of Product and Brand Management, Vol. 23 No. 1, pp. 62-74.

Hollebeek, L.D., Glynn, M.S. \& Brodie, R.J. (2014), “Consumer brand engagement in social media: Conceptualization, scale development and validation”, Journal of Interactive Marketing, Vol. 28 No. 2, pp. 149-165.

Hollebeek, L.D., Srivastava, R.K. \& Chen, T. (2016), “S-D logic-informed customer engagement: integrative framework, revised fundamental propositions, and application to CRM", Journal of the Academy of Marketing Science, doi:10.1007/s11747-016-0494-5. 
Jaakkola, E. \& Alexander, M. (2014), "The role of customer engagement behavior in value co-creation: A service system perspective”, Journal of Service Research, Vol. 17 No. 3 , pp. 247-261.

Jackson, S.E. \& Schuler, R.S. (1985), “A meta-analysis and conceptual critique of research on role ambiguity and role conflict in work settings", Organizational Behavior and Human Decision Processes, Vol. 36 No. 1, pp. 16-78.

Jahn, B. and Kunz, W. (2012), "How to transform consumers into fans of your brand", Journal of Service Management, Vol. 23 No. 3, pp. 344-361.

Juric, B., Wilks, G. and Smith, S. (2016), "Negative customer brand engagement: An overview of conceptual and blog-based findings", in Brodie, R.J., Hollebeek, L.D. and Conduit, J. (Eds.), Customer engagement: Contemporary issues and challenges, Routledge, Singapore. pp. 272-286.

Kjellberg, H. and Helgesson, C.F. (2006), "Multiple versions of markets: Multiplicity and performativity in market practice", Industrial Marketing Management, Vol. 5 No. 7, pp. 839-855.

Klijn, F. (1994), "Spatially nested ecosystems: Guidelines for classification from a hierarchical perspective", Ecology \& Environment, Vol. 2, pp. 85-116.

Koch, J. (1997), "Candidate gender and women's pyshcological engagement in politics", American Politics Research, Vol. 25 No. 1, pp. 118-133.

Koskela-Huotari, K., Edvardsson, B., Jonas, J. M., Sörhammar, D., \& Witell, L. (2016). "Innovation in service ecosystems - Breaking, making, and maintaining institutionalized rules of resource integration", Journal of Business Research, Vol. 69 No. 8, pp. 2964-2971.

Koskela-Huotari, K., and Vargo, S.L. (2016), "Institutions as resource context”, Journal of Service Theory and Practice, Vol. 26 No. 2, pp. 163-178.

Kumar, V., Aksoy, L., Donkers, B., Venkatesan, R., Wiesel, T., \& Tillmanns, S. (2010), "Undervalued or Overvalued Customers: Capturing Total Customer Engagement Value”, Journal of service research, Vol. 13 No. 3, pp. 297-310.

Kumar, V. and Pansari, A. (2015), “Competitive advantage through engagement", Journal of Marketing Research, in press, DOI: http://dx.doi.org/10.1509/jmr.15.0044.

Lawrence, T.B. and Suddaby, R. (2006), Institutions and institutional work, Sage, London.

Lawrence, T., Suddaby, R., \& Leca, B. (2011). "Institutional work: Refocusing institutional studies of organization”, Journal of Management Inquiry, Vol. 20 No. 1, pp. 52-58.

Lee, M.S.W., Motion, J. and Conroy, D. (2009), "Anti-consumption and brand avoidance", Journal of Business Research, Vol. 62 No. 2, pp. 169-180.

Lapinski, M. K., \& Rimal, R. N. (2005), “An explication of social norms”, Communication Theory, Vol. 15 No. 2, pp. 127-147. 
Li, L. P., Juric, B., \& Brodie, R. J. (2017). Dynamic multi-actor engagement in networks: the case of United Breaks Guitars. Journal of Service Theory and Practice, Vol. 27, No.4, pp. $761-777$

Lusch, R.F. and Vargo, S.L. (2014), Service-dominant logic: Premises, perspectives, possibilities, Cambridge University Press, Cambridge.

Marks, S.R. (1977), "Multiple roles and role strain: Some notes on human energy, time and commitment", American Sociological Review, Vol. 42 No. 6, pp. 921-936.

Munro, R. (2009), “Actor-network theory”, in Clegg, S.R. and Haugaard, M. (Eds.), The Sage Handbook of Power, Sage, London, pp. 125-139.

Naumann, K., Bowden, J., and Gabbott, M. (2017), “A Multi-Valenced Perspective on Consumer Engagement Within a Social Service”, Journal of Marketing Theory and Practice, Vol. 25 No. 2, pp. 171-188.

Oliver, C. (1992), “The antecedents of deinstitutionalization”, Organization Studies, Vol. 13 No. 4, pp. 563-588.

Paulin, M., Ferguson, R.J., Jost, N. and Fallu, J.M. (2014), "Motivating millennials to engage in charitable causes through social media", Journal of Service Management, Vol. 25 No. 3, pp. 334-348.

Philips, J. (2012). "Mumsnet and the politics of parent power", Retrieved from https://www.totalpolitics.com/articles/interview/mumsnet-and-politics-parent-power

Schau, H.J, Muñiz, A.M., Jr. and Arnould, E.J. (2009), "How brand communities create value", Journal of Marketing, Vol. 73 No. September, pp. 30-51.

Schulze, E.D. and Mooney, H.A. (2012) (Eds.), Biodiversity and ecosystem function, New York: Springer.

Shamir, B. (1980), "Between service and servility: Role conflict in subordinate service roles", Human Relations, Vol. 33 No. 10, pp. 741-756.

Solomon, M.R., Surprenant, C., Czepiel, J.A. and Gutman, E.G. (1985), “A role theory perspective on dyadic interactions: The service encounter", Journal of Marketing, Vol. 49 No. 1, pp. 99-111.

Storbacka, K., Brodie, R.J., Böhmann, T., Maglio, P.P. and Nenonen, S. (2016), “Actor engagement as a microfoundation for value co-creation: Conceptual directions for further research on SDL", Journal of Business Research, Vol. 69 No. 8, pp.3008-3017

Stryker, S., \& Macke, A. S. (1978), "Status inconsistency and role conflict", Annual Review of Sociology, Vol. 4 No. 1, pp. 57-90.

Sweeney, J.C., Danaher, T.S. and McColl-Kennedy, J.R. (2015), "Customer effort in value cocreation activities: Improving quality of life and behavioral intentions of healthcare customers", Journal of Service Research, Vol. 18 No. 3, pp. 318-335. 
Van Doorn, J., Lemon, K.N., Mittal, V., Nass, S., Pick, D., Pirner, P. and Verhoef, P.C. (2010), "Customer engagement behavior: Theoretical foundations and research directions", Journal of Service Research, Vol. 13 No. 3, pp. 253-266.

Vargo, S.L. and Lusch, R.F. (2004), "Evolving to a new dominant logic for marketing", Journal of Marketing, Vol. 68 No. 1, pp. 1-17.

Vargo, S.L. and Lusch, R.F. (2008), "Service-dominant logic: Continuing the evolution", Journal of the Academy of Marketing Science, Vol. 36 No. 1, pp. 1-10.

Vargo, S. L., \& Lusch, R. F. (2016), "Institutions and axioms: an extension and update of service-dominant logic", Journal of the Academy of Marketing Science, Vol. 44 No. 1, pp. 5-23.

Vargo, S. L., \& Lusch, R. F. (2017), “Service-Dominant Logic 2025”, International Journal of Research in Marketing, Vol. 34 No. 1, pp. 46-67.

Vargo, S.L., Wieland, H. \& Akaka, M.A. (2015), "Innovation through institutionalization: A service ecosystems perspective", Industrial Marketing Management, Vol. 44 No. 1, pp. 63-72.

Venkatesan, R. (2017), "Executing on a customer engagement strategy", Journal of the Academy of Marketing Science, Vol. 45 No. 3, pp. 289-293.

Verhoef, P. C., Reinartz, W. J., \& Krafft, M. (2010), “Customer Engagement as a New Perspective in Customer Management", Journal of service research, Vol. 13 No. 3, pp. 247-252.

Verleye, K. (2015), “The co-creation experience from the customer perspective: Its measurement and determinants", Journal of Service Management, Vol. 26 No. 2, pp. 321-342.

Verleye, K., Gemmel, P. and Rangarajan, D. (2014), "Managing engagement behaviors in a network of customers and stakeholders: Evidence from the nursing home sector", Journal of Service Research, Vol. 17 No. 1, pp. 68-84.

Vivek, S. D., Beatty, S. E., \& Morgan, R. M. (2012). Customer engagement: Exploring customer relationships beyond purchase. Journal of Marketing Theory and Practice, Vol.20 No.2, pp.122-146.

Vivek, S.D, Vivek, D. and Beatty, S.E. (2016), "Partner engagement - A perspective on B2B engagement", in Brodie, R.J., Hollebeek, L., Conduit, J. (Eds.), Customer Engagement: Contemporary Issues and Challenges, Routledge, UK, pp. 53-66. 
Table 1. Engagement research foci viewed from different levels of aggregation.

\begin{tabular}{|c|c|c|c|}
\hline $\begin{array}{l}\text { Level of } \\
\text { aggregation }\end{array}$ & Key focus & Aspects of engagement illuminated & Current state of engagement research \\
\hline Meso view & $\begin{array}{l}\text { Service ecosystem layer } \\
\text { forming the context around } \\
\text { the engagement object, } \\
\text { such as a brand community. }\end{array}$ & $\begin{array}{l}\text { The immediate context surrounding an } \\
\text { engagement object. Specific institutions and } \\
\text { institutional arrangements reinforce or } \\
\text { guide, but are also shaped by, engagement } \\
\text { behaviors. }\end{array}$ & $\begin{array}{l}\text { - Empirical research on how participation in a brand community } \\
\text { affects consumer engagement (Brodie et al, 2013). } \\
\text { - Empirical research on interactive engagement practices that } \\
\text { illustrate the impact of institutions (e.g. Li et al. 2017). } \\
\text { - Limited research addressing institutions or other governance } \\
\text { mechanisms for engagement (Storbacka et al., 2016). }\end{array}$ \\
\hline Macro view & $\begin{array}{l}\text { Service ecosystem layer } \\
\text { focusing on the broader } \\
\text { category or industrial } \\
\text { context of the engagement } \\
\text { object, such as a product } \\
\text { group or an industry. }\end{array}$ & $\begin{array}{l}\text { The broader ecosystem sharing a set of } \\
\text { higher level institutional arrangements (e.g. } \\
\text { industry standards or social norms) where } \\
\text { each engagement context and its associated } \\
\text { set of institutions are embedded in. }\end{array}$ & $\begin{array}{l}\text { - Lack of research addressing the broader category or industrial } \\
\text { context of the engagement object. }\end{array}$ \\
\hline
\end{tabular}


JOSM-08-2016-0237.R1 Response to Reviewer

We thank both reviewers for the positive evaluation of our paper. We thank reviewer 2 for additional comments and have revised the paper as specified below:

- The use of 'engagement context' appear several times without any definition or description. The authors should define/describe the term or use the more common 'in the context where actors are engaged'.

Response: Thank you for noticing this. To ensure a parsimonious narrative we felt engagement context was the more efficient term but we recognize it needs a little explanation. We have altered the text at the bottom of page one as follows:

"An ecosystem view highlights that each actor is involved in a multitude of co-existing value creation processes with other actors (Vargo and Lusch, 2016), suggesting that they face multiple, potentially conflicting, contexts where they are engaged (which we term engagement contexts).

- The sentence 'A critical development was a paper by Brodie et al...' reads odd. Please rephrase ( $p .4$ row 21/22)

Response: We agree, the sentence now starts "Brodie et al. (2011a) provide conceptual foundations..."

- In the definition of AEB (p. 6 row 14) the authors use 'resource contribution' in the definition. Since you are drawing on S-D logic, why not use 'resource integration' as a known term instead of introducing a new term?

Response: Thank you for this suggestion. While we agree that in S-D logic, resource integration is an established concept, we maintain that "resource contribution" is better aligned with extant engagement conceptualizations. Previous engagement research defines customer engagement as "resource contributions " as is apparent in the following definitions:

CEB is "behavior through which customers make voluntary resource contributions that have a brand or film focus but go beyond what is fundamental to transactions (Jaakkola \& Alexander 2014, p. 248)

"We therefore define customer engagement as a customer's voluntary resource contribution to a firm's marketing function, going beyond financial patronage". (Harmeling et al., 2016)

"customers choose to invest ... resources in particular brand interactions" (Hollebeek et al. 2016, p. 3)

Similarly, we define actor disengagement behavior as 'an actor's temporary or permanent removal of resource contributions' - here 'integration' would not make sense.

- The sentence 'This analysis shows that engagement .... have as yet been not been addressed....' seems odd, please rephrase.

Response: Sentence has been adapted: "This analysis suggests that given the predominant micro level focus of extant engagement research, institutional contexts - as well as the existence of multiple, parallel engagement contexts - have not yet been addressed." 
References:

Harmeling, C. M., Moffett, J. W., Arnold, M. J., \& Carlson, B. D. (2017). Toward a theory of customer engagement marketing. Journal of the Academy of Marketing Science, 45(3), 312-335.

Hollebeek, L. D., Srivastava, R. K., \& Chen, T. (2016). SD logic-informed customer engagement: integrative framework, revised fundamental propositions, and application to CRM. Journal of the Academy of Marketing Science.

Jaakkola, E., \& Alexander, M. (2014). The role of customer engagement behavior in value co-creation a service system perspective. Journal of Service Research, 17(3), 247-261. 